\title{
Study of Different Control Methods of Active Power Filter for Harmonic Reduction
}

\author{
Ankita Pol, S. S. Karvekar \\ Department of Electrical Engineering, Shivaji University, \\ Walchand College of Engineering, Sangli, India.
}

\begin{abstract}
A theoretical study of various control strategies to extract reference current for Active Power Filter (APF) is given in this paper. This paper presents various type of approaches, methods and techniques in detail. The study also helps the to choose the correct control solutions and power circuit design for APF applications.
\end{abstract}

Keywords - Harmonic Reduction, Shunt Active Power Filter, Reference current, Fundamental current, Fourier Transform, PQ Theory, Wavelet Transform.

\section{INTRODUCTION}

Almost nineteen years ago, loads used by industry and customers were linear and passive. Therefore the impact of nonlinear loads on the power system has been less significant. Recently, the development of semiconductor devices has become more advantageous. In addition, various power electronic devices and electronic control tools are used to increase the efficiency of the non-conventional energy sources [1]. Even though, the benefits of using the aforementioned devices are certainly good but there are some demerits of excessive usage of electronic power devices. Because of the power electronic devices, harmonics is a big problem in control systems. Harmonics get entered into power system via a point of common coupling. These harmonics result in further losses, overheating, and overloading [2]. As a result, problems of power quality are increasing more and more. It also causes transient disturbances and reduces efficiency. The use of the above mentioned electronic devices is responsible for harmonic disturbances as well as reactive power disturbances. Harmonics and reactive power is the main reason various problems including transformer overheating, feeder voltage distortion, excess amount of neutral current, malfunction of sensitive equipment, poor power factor and damage to electronic devices[2]. A lot of conventional solutions to these problems have been introduced. A passive power filters and capacitors are the simplest traditional methods to lower the harmonics and increase the power factor. But the system becomes bulky because of condensers and inductors and it also causes resonance which makes the system more unstable. Later, Static var compensators with several power factor correction configurations are added. But some SVC configurations have very long response time so they are not suitable for fast fluctuating loads as well as harmonics of lower order. Several methods of harmonic reduction are developed using the power electronics technique to solve harmonic problems.

\section{DIFFERENT CONTROL STRATERGIES}

A. Multiplication with Sine Function

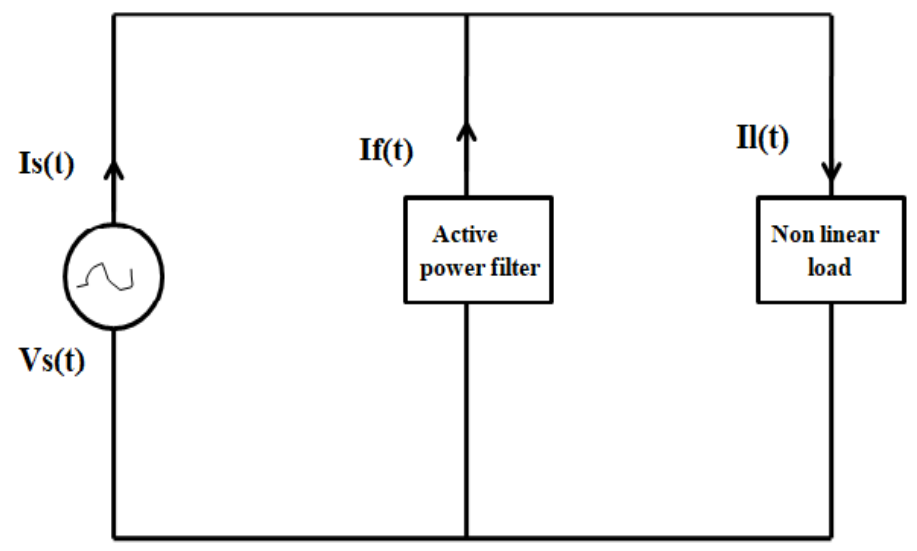

Fig.1. Diagram of power stages of active filter

Above figure shows block diagram of power stage of shunt active power filter. Under normal conditions, the source voltage is represented by equation (1) [4]-[6]

$\mathrm{Vs}(\mathrm{t})=\mathrm{Vm} * \sin \omega \mathrm{t}$

and load current produced by nonlinear load is represented by equation,

$i_{L}(t)=i_{o}(t)+i_{p}(t)+i_{q}(t)+i_{h}(t)$

This current equation is composition of four current components which are dc component, active component, reactive component and harmonic component respectively. In general we write above equation (2) as follows,

$i_{L}(t)=\sum_{n=1}^{\infty} I_{n} \sin \left(n \omega t+\theta_{n}\right)$ 


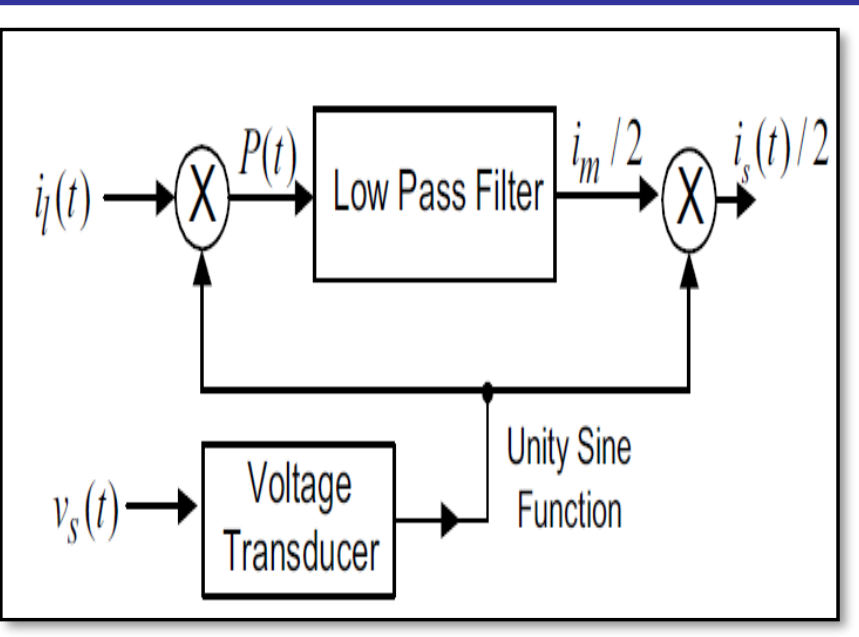

Fig. 2. block diagram of proposed scheme

Above figure represents basic diagram of proposed technique. As shown in the figure load current is multiplied by unity sine function. Sine function is in the phase with source voltage. This product output given to low pass filter and it is denoted by $P(t)$ and it is represented by,

$$
\begin{aligned}
P_{L}(t)= & V_{s}(t) i_{L}(t) \\
P_{L}(t)= & V_{m} \sin (w t) * \sum_{n=1}^{\infty} I_{n} \sin \left(n \omega t+\theta_{n}\right) \\
& =I_{1} V \sin \sin ^{2} \omega t \cos \theta_{1}+I_{1} V \sin \sin \omega t \cos \omega t \sin \theta_{1} \\
& +\sum_{n=2}^{\infty} V_{m} \sin \omega t I_{n} \sin \left(n \omega t+\theta_{n}\right)
\end{aligned}
$$

$P_{L}(t)=p_{s}(t)+p_{c}(t)$

Where,

$$
\begin{aligned}
& p_{s}(t)=I_{1} V \operatorname{sm} \sin ^{2} \omega t \cos \theta_{1} \\
& p_{c}(t)=I_{1} V \operatorname{sm} \sin \omega t \cos \omega t \sin \theta_{1} \\
& +\sum_{n=2}^{\infty} V_{m} \sin \omega t I_{n} \sin \left(n \omega t+\theta_{n}\right)
\end{aligned}
$$

$p_{s}(t)$ represents real power and $p_{c}(t)$ represents supplied by source combination of reactive and harmonic power. As filter provides reactive and harmonic power, the current supplied from source side is given by

$i_{S}(t)=\frac{p_{S}(t)}{V_{S}(t)}=I_{1} \cos \theta_{1} \sin \omega t=I_{S} \sin \omega t$

Where,

$I_{s}=I_{1} \cos \theta_{1}$

The current $i_{s}(t)$ is in phase with the source voltage and it is sinusoidal. At the same time, the Active Power Filter (APF) should inject compensation current which is given by following equation:

$$
i_{c}(t)=i_{L}(t)-i_{s}(t)
$$

From figure, output of low pass filter is multiplied by unity sine function. The low pass filter output will have value half of the load current peak value of given by the following equation,

$$
\int_{t}^{T+t} \mathrm{i}_{1}(\mathrm{t}) \sin (\omega t) d t=I_{s} / 2
$$

The load current equation in (12) should be periodic with period $T / 2$. So, source current will set a new value according to load current over a half period of cycle. If even harmonics are present the load current, full cycle integration is required. Source current is estimated with the help of product of low pass filter output and a sine function. Under distorted voltage, along with fundamental component load current harmonic component also supplies to average load power. Hence during distorted supply, alternative methods should be used to produce the reference source current.

\section{B. $P Q$ Transformation}

Akagi have presented the theory of the instantaneous reactive power for three phase system. It is also called as p-q theory [7]-[8]. This theory consists of an algebraic transformation of the three phase quantities ( $a-b-c$ coordinates) to the two phase quantities ( $\alpha-\beta-0$ coordinates). The $p-q$ theory implements the Clarke transformation that projects three phase quantities into the stationary reference frame with the help of real matrix.

1) The clarke transformation: The Clarke transformation transforms the three phase instantaneous voltages i.e. $\mathrm{Va}, \mathrm{Vb}$

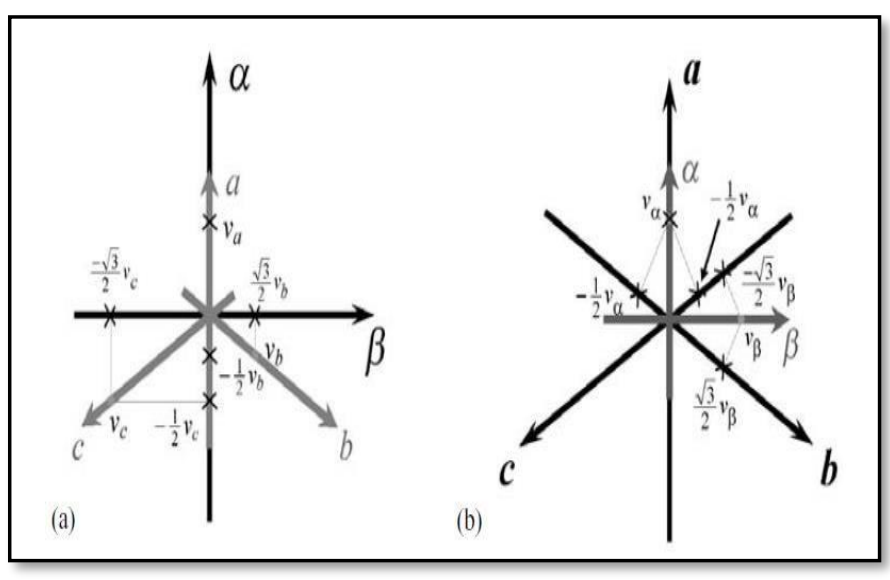

Fig.3. Phasor representation of axes transformation

and $\mathrm{Vc}$ into two phase instantaneous voltages i.e. $\mathrm{Vo}, \mathrm{V} \alpha$ and $\mathrm{V} \beta$ respectively on $\alpha \beta 0$-axes. The Clarke Transformation and its inverse transformation is given as follows,

$$
\left[\begin{array}{c}
\cdots-v_{0} \\
v_{\alpha} \\
v_{\beta}
\end{array}\right]=\sqrt{\frac{2}{3}}\left[\begin{array}{ccc}
\frac{1}{\sqrt{2}} & \frac{1}{\sqrt{2}} & \frac{1}{\sqrt{2}} \\
1 & -\frac{1}{2} & -\frac{1}{2} \\
0 & \frac{\sqrt{3}}{2} & -\frac{\sqrt{3}}{2}
\end{array}\right]\left[\begin{array}{c}
v_{a} \\
v_{b} \\
v_{c}
\end{array}\right]
$$

$$
\left[\begin{array}{l}
v_{a} \\
v_{b} \\
v_{c}
\end{array}\right]=\sqrt{\frac{2}{3}}\left[\begin{array}{c:cc}
\frac{1}{\sqrt{2}} & 1 & 0 \\
\frac{1}{\sqrt{2}} & -\frac{1}{2} & \frac{\sqrt{3}}{2} \\
\frac{1}{\sqrt{2}} & -\frac{1}{2} & -\frac{\sqrt{3}}{2}
\end{array}\right]\left[\begin{array}{c}
-v_{0} \\
v_{\alpha} \\
v_{\beta}
\end{array}\right]
$$

One advantage to use the $\alpha \beta 0$ transformation is that it helps to segregate zero sequence components from the three phase abc quantities. The $\alpha$ and $\beta$ axes contains positive sequence and negative sequence components respectively. For balanced three phase voltage system the Clarke transformation and its inverse is written as follows respectively. The matrices in (15) and (16) are axes-transformation of three phase abc coordinates to $\alpha \beta 0$ frame as given in Fig. 3. $\alpha \beta 0$ axis is a static frame. The a, b and c axes are spatially separated by 120 
degrees from each other and $\alpha \beta 0$ axes are shifted by 90 degrees apart from each other.

$$
\left[\begin{array}{l}
v_{\alpha} \\
v_{\beta}
\end{array}\right]=\sqrt{\frac{2}{3}}\left[\begin{array}{rrr}
1 & -\frac{1}{2} & -\frac{1}{2} \\
0 & \frac{\sqrt{3}}{2} & -\frac{\sqrt{3}}{2}
\end{array}\right]\left[\begin{array}{l}
v_{a} \\
v_{b} \\
v_{c}
\end{array}\right]
$$

$$
\left[\begin{array}{l}
v_{a} \\
v_{b} \\
v_{c}
\end{array}\right]=\sqrt{\frac{2}{3}}\left[\begin{array}{cc}
1 & 0 \\
-\frac{1}{2} & \frac{\sqrt{3}}{2} \\
-\frac{1}{2} & -\frac{\sqrt{3}}{2}
\end{array}\right]\left[\begin{array}{l}
v_{\alpha} \\
v_{\beta}
\end{array}\right]
$$

2) The $p-q$ Theory: The $p-q$ Theory [9],[30] is explained for three phase system. Three instantaneous powers quantities are given as in zero sequence power $p 0$, real power $p$ and the instantaneous imaginary power $q$.

$$
\left[\begin{array}{c}
p_{0} \\
\hdashline p \\
q
\end{array}\right]=\left[\begin{array}{c:cc}
v_{0} & 0 & 0 \\
\hdashline 0 & v_{\alpha} & v_{\beta} \\
0 & v_{\beta} & -v_{\alpha}
\end{array}\right]\left[\begin{array}{c}
i_{0} \\
\hdashline i_{\alpha} \\
i_{\beta}
\end{array}\right]
$$

If zero sequence components (current and voltages) are absent in three phase three wire system (i.e. $i_{0}=0$ ) then we get only the instantaneous power on the axes. Hence the energy per unit time is represented by the instantaneous real power $p$ for three phase three wire systems. Now relation between the real and imaginary power component $\mathrm{p}$ and $\mathrm{q}$ respectively is given as follows,

$$
\left[\begin{array}{l}
p \\
q
\end{array}\right]=\left[\begin{array}{cc}
v_{\alpha} & v_{\beta} \\
-v_{\beta} & v_{\alpha}
\end{array}\right]\left[\begin{array}{l}
i_{\alpha} \\
i_{\beta}
\end{array}\right]
$$

Both the powers $\mathrm{p}$ and $\mathrm{q}$ contains fixed value and a oscillating components and mathematically it can be expressed as follows:

$$
\begin{aligned}
& p=\bar{p}+\tilde{p} \\
& q=\bar{q}+\tilde{q}
\end{aligned}
$$

Similarly, for three phase four wire system a zero sequence power quantity is written as addition of a constant and oscillating components given by equation (20)

$$
p_{0}=\bar{p}_{0}+\widetilde{p}_{0}
$$

3) P-Q theory to Active Power Filters: only $p$ and $p_{0}$ are useful quantities among all the power quantities obtained by using the $p$-q theory because they represents transfer of energy from the source side to the load side. Other power quantities are compensated by shunt active power filter as shown fig 4 . From fig. 4 we can see the power $p_{0}$ is transferred from the source side to the active power filter via $\alpha-\beta$ coordinates. After that this power is given to load side by active power filter via $O$ coordinate. The dc capacitors are used to compensate oscillating power $p \sim$ and $p_{0}^{\tilde{0}}$. These power quantities are stored in the capacitor and later on transferred to the load side. Capacitors are not required for the compensation of instantaneous imaginary power $(q)$ which contains the reactive power component. Shunt active power filter eliminates only harmonic components. Instantaneous reactive power theory is not applicable for reactive power compensation. Hence another auxiliary circuit is required for c6lfpensation of reactive power component. Hence a hybrid filter can be designed by using passive filter in synchronization with active power filter. These hybrid filters perform both harmonic and reactive power compensation. It also helps to improve power factor. This method have fast response time over the other techniques. One demerit of this method is that its algorithm cannot regenerate sinusoidal source current under deformed source voltage. Hence, practically this algorithm is not applicable to distribution systems where some distorted voltage is available in PCC voltage.

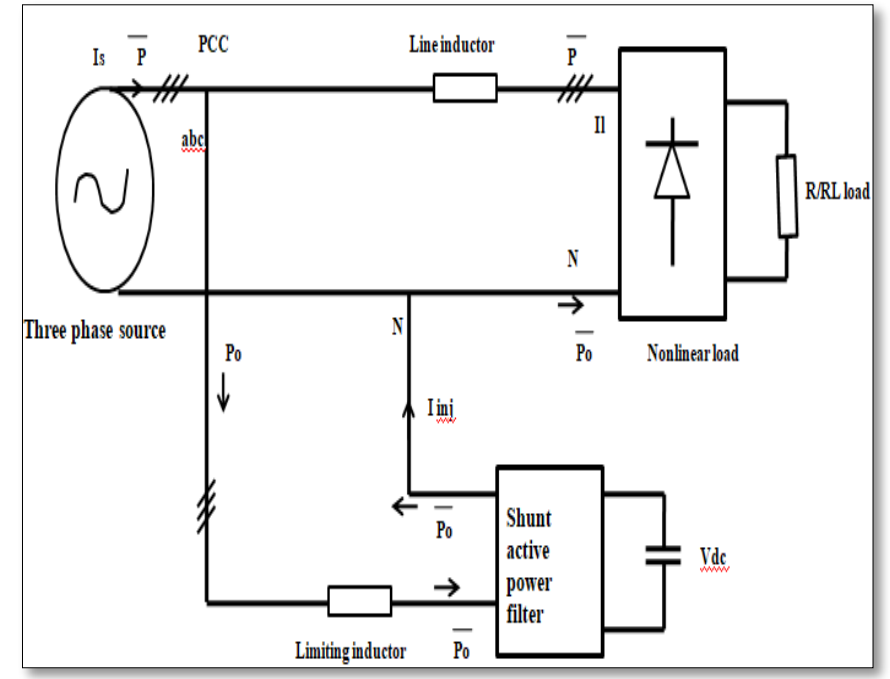

Fig.4 Implementation of pq theory to shunt active power filter

\section{Fourier Transform method}

It is easy and basic algorithm which is based on Fourier transform technique. This technique produces the reference current even under the distorted supply [10]-[11]. This method also gives a better transient response to load current. If load current contains odd harmonics then it gives better transient response for half cycle and if load current carries even harmonics then it gives good transient response for one cycle. Let us Assume the supply voltage is rigid because of the source inductance and capacitance. As shown in fig. 5 the 
source side supplies a nonlinear load. Nonlinear load consists of a bridge rectifier with load ( $\mathrm{R}, \mathrm{RL}$, etc). An active power filter is connected to the PCC via a inductor. The filter is used is nothing but a voltage source inverter (VSI) which supplies the harmonics and reactive quantities.

In general, source voltage and load current can be written as follows which is given by equation (21) and (22) respectively, $\mathrm{v}_{\mathrm{s}}(\mathrm{t})=\mathrm{V}_{\mathrm{dc}}+\mathrm{V}_{\mathrm{m} 1} \sin \left(\omega \mathrm{t}+\varphi_{1}\right)+\mathrm{V}_{\mathrm{m} 2} \sin \left(2 \omega \mathrm{t}+\varphi_{2}\right)+\cdots+$ $\mathrm{V}_{\mathrm{mn}} \sin \left(\mathrm{n} \omega \mathrm{t}+\varphi_{\mathrm{n}}\right)$

$$
\begin{aligned}
\mathrm{i}_{\mathrm{l}}(\mathrm{t})= & \mathrm{I}_{\mathrm{dc}}+\mathrm{I}_{\mathrm{m} 1} \sin \left(\omega \mathrm{t}+\varphi_{1}\right)+\mathrm{I}_{\mathrm{m} 2} \sin \left(2 \omega \mathrm{t}+\varphi_{2}\right)+ \\
& \ldots+\mathrm{I}_{\mathrm{mn}} \sin \left(\mathrm{n} \omega \mathrm{t}+\varphi_{\mathrm{n}}\right)
\end{aligned}
$$

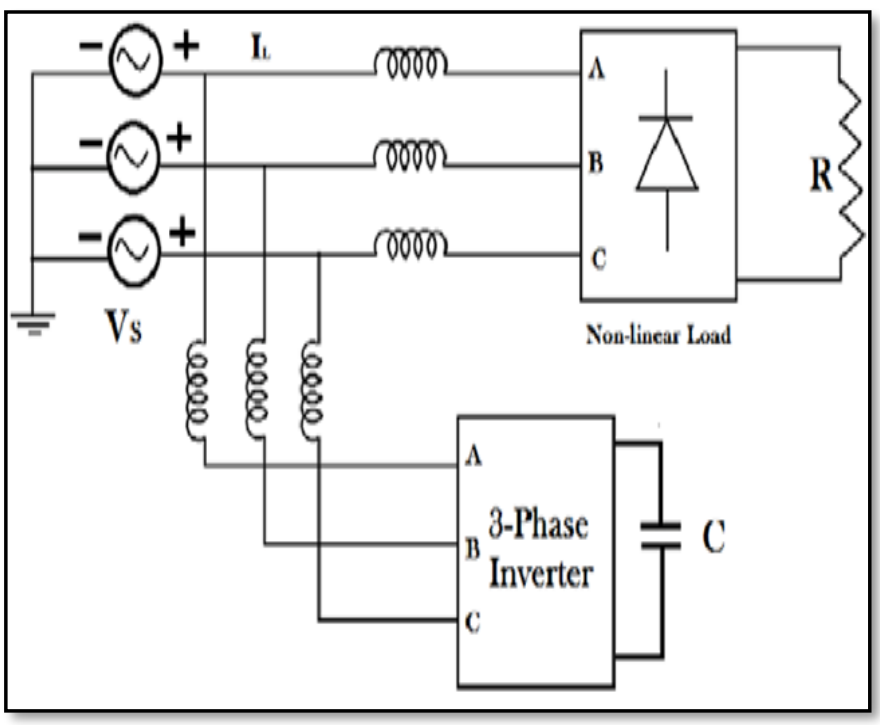

Fig. 5. Basic diagram of three phase source with nonlinear load

The terms $V_{d c}$ and $I_{d c}$ be the dc component of supply voltage and load current, respectively. The average power utilized by the load side is estimated by using following equation,

$P_{\text {lavg }}=1 / T \int_{t}^{T+t} \mathrm{v}_{\mathrm{s}}(\mathrm{t}) \mathrm{i}_{\mathrm{l}}(\mathrm{t}) d t$

Where,

$\mathrm{T}$ represents total time of voltage or current quantities and $\mathrm{t}$ represents any time. Summing over the half cycle is carried out if the load current carries odd harmonics. Apart from this, the source side injects the losses $\left(P_{\text {loss }}\right)$ to the inverter. Loss components are obtained from Proportional Integral (PI) controller loop in the inverter [7],[12]. The overall power $P_{S}$ delivered by the source is given as follows:

$P_{s}=P_{\text {lavg }}+P_{\text {loss }}$

The magnitude of $P_{\text {loss }}$ is less as compared to the average load power $P_{\text {lavg }}$. Hence the effect of inverter losses is less on the transient response of the system. The active power filter draws only load current fundamental component. Now the relation between sinusoidal source current with and a source power $P_{S}$ is given by (25)

$\frac{I_{m s} v_{m 1} \cos \varphi_{s}}{2}=P_{s}$

Where,

$v_{m 1}=$ Fundamental peak component of the supply voltage
$I_{m s} \quad=$ source current peak value

$\cos \varphi_{\mathrm{s}}=$ power factor

Value of $v_{m 1}$ is calculated by Fourier transform is given by equation (26)

$C_{v 1}=1 / T \int_{t}^{T+t} e^{-j\left(w t-\frac{\pi}{2}\right)} \mathrm{v}_{\mathrm{s}}(\mathrm{t}) d t$

Value of $v_{S}(t)$ is taken from equation (21). After solving above equation we get,

$C_{v 1}=\frac{v_{m 1}}{2}<\varphi_{1}$

The term $C_{v 1}$ represents a complex number with value $\frac{v_{m 1}}{2}$ and phase of $\varphi_{1}$. From (27), the fundamental peak component of the supply voltage is represented by (28).

$\left|v_{m 1}\right|=2 *\left|C_{v 1}\right|$

Using equation (26), (27) and (28) we can calculate fundamental peak value of source current. In the time domain equation (25) is written as

$i_{\mathrm{s}}^{*}(\mathrm{t})=\mathrm{I}_{\mathrm{ms}} \sin \left(\mathrm{wt}-\varphi_{\mathrm{s}}\right)$

From equation (29) the compensating reference current is calculated as follows,

$i_{\mathrm{f}}^{*}(\mathrm{t})=\mathrm{i}_{\mathrm{i}}^{*}(\mathrm{t})-\mathrm{i}_{\mathrm{s}}^{*}(\mathrm{t})$

\section{Wavelet Transform}

A Wavelet Transform (WT) method [13]-[18] is used to extract fundamental component of frequency from three phase unbalanced and non sinusoidal load current. Multi resolution analysis (MRA) [15] method is used to extract fundamental component of frequency is shown in fig. 6 . The constructed controller have good frequency bandwidth selection. The controller tuning parameters are used as inputs to time frequency signals. The extraction using FFT gives incorrect outputs if the signals are distorted. One of the disadvantage of Fourier transform is that points observed in a observation window should be proportional to the numbers of samples per time. If the points in the observation window are not in proportion with number of sample per period it leads to inaccuracy in the extraction. The Wavelet Transform method helps to minimize the above demerit. Wavelet analysis is a new method to applied mathematics [18]. The voltage and current quantities are transferred to the time and frequency axes using the complex wavelet with the help of scaling and translation factors [19].

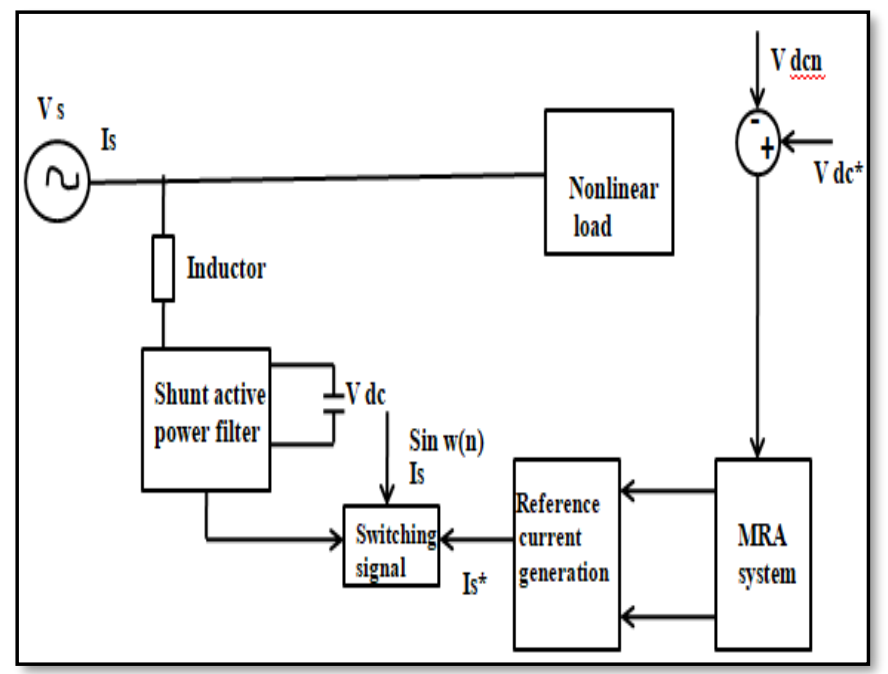

Fig. 6 Block diagram of application of wavelet transform technique to active power filter 


\section{CONCLUSION}

1. This paper gives variety of compensation methods for three phase active power filter. The multiplication of sine function is very simple and easy method among all. Voltage related information is not required in this method for calculation. . If load current contains odd harmonics then algorithm provides good response time for half period of cycle and if load current contains even harmonics then it gives good response time for one cycle. But both algorithms give unsatisfactory performance for deformed supply.

2. The pq theory is a fast method. But it also unable to regenerate sinusoidal source current under distorted source voltage.

3. The Fourier transform technique and wavelet transform are good one among all other methods.

\section{REFERENCES}

[1] Hirofumi Akagi "New trends in Active Filters for Power conditioning", IEEE transactions on industry applications, vol 32 no 6, pp.1312-1322, Nov /Dec1996.

[2] Henderson and Rose "Harmonics: The Effects on Power Quality and Transformers". IEEE transactions on industry applications, vol. 30, no. 3, pp. 528-532, May/June1994.

[3] N. A. Rahim, Z. Islam, et al., "A new approach for harmonic compensation using single- phase hybrid active power filter" Paper ID: 1568963328 , pp. 1-5, April 30,2005.

[4] C. Y. Hsu and H. Y. Wu, "A new single phase active power filter withreduced energy storage capacity," IEE Proc.- Electric Power Application, Vol. 143, No. 1, pp. 25-30, January 1996

[5] J. A. Lambert, E. A. A. Coelho, J. B. Vieira Jr., and V. J. Farias, "Active power filter control based on imposition of input sinusoidal current," in Proc. PESC 97 Record 28th Ann. IEEE Power Electron. Specialists Conf., vol. 1, pp. 406-411.

[6] M. Saitou, N. Matsui, T. Shimizu, "A control strategy of single phase active filter using a novel d-q transformation," in Industry Application Conference 2003, pp. 1222-1227.

[7] H. Akagi, Y. Kanazawa, and A. Nabae, "Instantaneous reactive power compensators comprising switching devices without energy storage components," IEEE Trans. Ind. Appl. vol. IA-20, p. 625, 1984

[8] M. T. Haque, "Single Phase pq theory", Accepted for presentation in PESC'02, pp.1815-1820, 2002.

[9] H. Akagi "Instantaneous power theory and applications to power conditioning".

[10] Mahesh. K. Mishra, Linash. P. Kunjumuhammed, "Fast Transient Single Phase Active Power Filter", in Proc. IEEE Tencon'05 Nov 21-24 2005.

[11] M. Saitou, N. Matsui, and T. Shimizu, "A control strategy of single phase active filter using a novel d-q transformation," in Proc. Ind. Appl. Conf., 2003, pp. 1222-1227.

[12] Julio Barros, Senior Member, IEEE, Ramón I. Diego, Member, IEEE, and Matilde de Apráiz "Applications of Wavelet Transform for Analysis of Harmonic Distortion in Power Systems: A Review", IEEE Trans. on instrumentation and measurement, vol. 61 , no. 10 , pp. 2604-2611, october 2012.

[13] A. M. Massoud, $\boldsymbol{S}$. J. Finney and B. W. Williams "Review of Harmonic Current Extraction Techniques for an Active Power Filter", 2004 11th International Conference on Harmonies and Quality of Power, p.p 154-159.

[14] K. G. Firouzjah, A. Sheikholeslami, M. R. Karami-Mollaei , “A New Harmonic Detection Method for Shunt Active Filter Based on Wavelet Transform," Journal of Applied Sciences Research, 4(11): 1561-1568, 2008 (C) 2008, insinet Publication

[15] Hui Liu, Guohai Liu and Yue Shen, "A Novel Harmonics Detection Method Based on Wavelet Algorithm for Active Power Filter", Proceedings of the 6th World Congress on Intelligent Control And Automation, June 21 - 23, 2006, Dalian, China
[16] Mehdi Forghani and Saeed Afsharnia "Online Wavelet Transform-Based Control Strategy for UPQC Control System" IEEE Trans. on power delivery, vol. 22, no. 1, p.p 481-491, january 2007

[17] karunesh K Gupta, Rajneesh Kumar , “Active Power Filter Control Algorithm using Wavelets" (C2006 IEEE.

[18] W. G. Morsi and M. E. El-Hawary, "A new perspective for the IEEE Standard 1459-2000 via stationary wavelet transform in the presence of nonstationary power quality disturbance," IEEE Trans. Power Del., vol. 23, no. 4, pp. 2356-2365, Oct. 2008

[19] Papan Dey, Saad Mekhilef. "Current Controllers of Active Power Filter for Power Quality Improvement: A Technical Analysis", Automatika, 2017

[20] Varaprasad, O V S R, and D V S S Siva Sarma. "An improved SVPWM based shunt active power filter for compensation of power system harmonics", 2014 16th International Conference on Harmonics and Quality of Power (ICHQP), 2014.

[21] Shivansh Srivastava, Yash Shah, et al.," Implementation and Simulation of Single Phase Active Shunt Power Filter" 1st IEEE International Conference on Power Electronics.,Intelligent Control and Energy Systems, pp. 1-4,(ICPEICES-2016).

[22] Chongming Qiao, Franco Maddaleno, et al., "A Single-Phase Active Power Filter With One-Cycle Control Under Unipolar Operation". IEEE transactions on circuits and systems I: regular papers, vol. 51, no. 8, pp. 1623-1630, August2004.

[23] Li, W., Rahmani, B., \& Liu, G. (2016). A Wavelet-Based Shun Active Power Filter to Integrate a Photovoltaic System to Power Grid. 2016 Sixth International Conference on Instrumentation \& Measurement, Computer, Communication and Control (IMCCC). doi:10.1109/imccc.2016.127

[24] S. K. Khadem, M. Basu and M. F. Conlon, "Harmonic power compensation capacity of shunt active power filter and its relationship with design parameters," IET Power Electronics. vol.7, pp. 418-430, 2014

[25] M. Fallah, J. Modarresi, A. Ajami, M. T. Bina, "Improvement of indirect harmonic compensation method using online discrete wavelet transform," Journal of circuit system and computers. 2015

[26] L.MuniaSelvan Dr.P.Rathika, "Harmonic Analysis Using Wavelet Transform for Active Power Filter Applications"

[27] Venkatasiva,Maheshbabu, "Design of Shunt Active Power Filter for Improvement of Power Quality with Artificial Intelligence Techniques," International Journal of Advance Research in Electrical and Electronics Engineering, Vol. 3, Issue 8, August 2014

[28] Viorel Apetrei1,Constantin Filote,Adrian Graur, "Harmonic Analysis Based on Discrete Wavelet Transform in Electric Power Systems," Ninth International Conference on Ecological Vehicles and Renewable Energies (EVER) 2014

[29] El-sotouhy, M. M., Zaki, A. M., Mansour, A. A., EL-Sattar, A. A., \& Marei, M. I. (2019). Active Filter Based on Four-Leg Inverte and PQ Theory. 2019 21st International Middle East Power Systems Conference (MEPCON)

[30] A. Mortezaei, C. Lute, M. G. Simões, F. P. Marafão, and A. Boglia, "PQ, DQ and CPT control methods for shunt active compensators - A comparative study," 2014 IEEE Energy Convers. Congr. Expo. ECCE 2014, pp. 2994-3001, 2014. 